\section{Pattern of congenital anomalies in newborn: a hospital-based study}

\author{
Mohamed A. EI Koumi, 1 \\ Ehab A. Al Banna, ${ }^{1}$ lbrahim Lebda 2 \\ Departments of 1 Pediatrics and \\ 2Diagnostic Radiology, Faculty \\ of Medicine, Zagazig University, Egypt
}

\section{Abstract}

Birth defects, encountered frequently by pediatricians, are important causes of childhood morbidity and mortality. Birth defects can be classified according to their severity, pathogenic mechanism, or whether they are involving a single system or multiple systems. This hospital-based prospective descriptive study highlights the prevalence of Congenital Anomalies (CAs) in one year among live born neonates delivered in Zagazig University Hospital (Egypt). All women giving birth to viable babies were included. Demographic details, associated risk factors and the type of CAs in all babies were recorded. Diagnosis of CAs was based on clinical evaluation, radiographic examination, ultrasonography, echocardiography and chromosomal analysis of the newborn whenever recommended. The overall incidence of CAs among live born neonates was $2.5 \%$, as most of the cases were referred to Zagazig University Hospital (Egypt) for delivery. The musculoskeletal system (23\%) was the most commonly involved followed by the central nervous system (20.3\%). Involvement of more than one system was observed in (28.6\%) cases. Among maternal and fetal risk factors; parental consanguinity, maternal under nutrition and obesity, positive history of an anomaly in the family, low birth weight, and prematurity were significantly associated with higher frequency of $\mathrm{CAs}$ $(\mathrm{P}<0.05)$, with non-significant differences for maternal age and the sex of the neonates. The current study highlights the prevalence of congenital anomalies in one year in Zagazig University Hospital. It revealed a high prevalence of congenital anomalies in our locality and stressed the importance of carrying out a thorough clinical examination of all neonates at birth.

\section{Introduction}

Birth defects are a diverse group of disorders of prenatal origin that can be caused by single gene defects, chromosomal disorders, multifactorial inheritance, environmental teratogens and micronutrient deficiencies. Maternal infections such as rubella, maternal illnesses like diabetes mellitus (DM), iodine and folic acid deficiency, exposure to medicinal and recreational drugs including alcohol and tobacco, certain environmental chemicals, and doses of radiation are all other factors that cause birth defects. ${ }^{1}$ Birth defects, congenital abnormalities and congenital anomalies (CAs) are interchangeable terms used to describe developmental defects that are present at birth. ${ }^{2}$ The rapid decline in the infant mortality and morbidity in developed countries has focused the attention of pediatricians on the problem of CAs. In the past, the causes of infant mortality were due to the prevalence of infectious diseases. The introduction of new antibiotics and advances made in the field of preventive medicine and immunology has changed this and it was found that deaths in infancy were due more to CAs than infectious diseases. ${ }^{3}$ This, however, may not be true for a developing country like Egypt. Despite epidemiological and medical advances in the causes and treatment of children with CAs, as well as increase in health policy initiatives, additional work must be carried out to improve the health of the nations' children, with special attention to birth defects. A better understanding and increased knowledge of the epidemiology of children with birth defects is a high priority due to the maternal and child health indicators in healthy people. ${ }^{4}$ CAs have been known and recognized for centuries. It is a stimulating problem for research because of the high frequency of their occurrence and the devastating effect they may have on the individual and his or her family. Considerable variation in frequency in different populations has been reported, from as low as 1.07\% in Japan to as high as $3 \%$ in Taiwan. This wide variability could be due to the different methodologies used in the different studies. ${ }^{5}$ This study was intended to document the pattern of CAs in newborns at birth in our locality in Egypt where, outside of the private medical services, there are no national policies nor consensus for prenatal diagnosis, nor prenatal intervention on the conceived babies with potential congenital anomalies. Thus, this study aimed to estimate of the true incidence of CAs in newborns in the absence of prenatal selection.

\section{Materials and Methods}

This prospective study was undertaken at Zagazig University Hospital, Zagazig Governorate, Egypt. All babies born in the obstetrics department from January 2011 to December 2011 were included in the study. Both the mother and her baby were examined
Correspondence: Mohamed A El Koumi, Zagazig University Children Hospital, Zagazig, Sharkia 44511, Egypt.

Fax: +20.2.055.2307830

E-mail: mohamed_197228@hotmail.com

Key words: anomalies, congenital, neonates.

Contributions: MAEK, conceptualized and designed the study, designed the data collection, carried out the initial analyses, drafted the initial manuscript, reviewed and revised the manuscript; $E A B$, shared designing of the study, carried out the initial analyses, drafted the initial manuscript, reviewed and revised the manuscript; IL, performed the radiological diagnosis, and revised the manuscript.

Conflict of interests: the authors declare no potential conflict of interests.

Received for publication: 6 December 2012

Revision received: 18 January 2013.

Accepted for publication: 18 January 2013.

This work is licensed under a Creative Commons Attribution NonCommercial 3.0 License (CC BYNC 3.0).

(C) Copyright M.A. El Koumi et al., 2013

Licensee PAGEPress, Italy

Pediatric Reports 2013; 5:e5

doi:10.4081/pr.2013.e5

as a unit within $24 \mathrm{~h}$ of birth and were further followed up for up to $72 \mathrm{~h}$. A detailed history was taken including familial and gestational factors, and a meticulous examination of baby was made. Twin deliveries were excluded. All neonates identified with CAs were admitted to NICU for observation, investigation, evaluation and management. Photographs, radiographs, ultrasound examinations, echocardiography, and chromosomal studies were included whenever recommended.

Cases with genetic syndromes were diagnosed by review of Mandelian inheritance in man and the London dysmorphology database. ${ }^{6}$ The major CAs were classified according to the ICD-10 system, and multiple major CAs were counted only once by the system for the most serious anomaly. ${ }^{7}$ Results were analyzed by simple statistical techniques recording number and percentage of cases. The two groups were compared using Student's t-test and ANOVA of $F$ test were used for comparison of more than two groups. $\mathrm{P}<0.05$ was considered significant.

\section{Results}

During this 1-year study, there were 2517 deliveries. Out of 2517 newborns, 63 had one 
or other congenital anomaly accounting for an incidence of $2.5 \%$. Out of these, 56 had a single congenital anomaly and the other 18 (28.6\%) had multiple malformations. Thus, there were a total of 74 anomalies among 63 newborn babies.

Table 1 summarizes the pattern of congenital malformations seen in neonates. The musculoskeletal system was the most commonly affected (23\%), followed by the central nervous system (CNS) (20.3\%), gastrointestinal system (GIT) (16.2\%), genitourinary system (13.5\%), craniofacial (10.8\%), cardiovascular system (CVS) (9.5\%), and chromosomal anomalies (6.8\%).

Table 2 summarizes the maternal and fetal factors associated with CAs at birth. Maternal age $(<20$ years or $>35$ years) was associated with increased incidence of CAs although this was not significant. There was significantly more CAs among neonates with parental consanguinity than among babies without parental consanguinity $(\mathrm{P}<0.05)$. Both maternal undernutrition and obesity were significantly associated with an increase in CAs among neonates $(\mathrm{P}<0.05)$. There were significantly more cases with a history of an anomaly in another child or in the family among mothers of neonates with CAs $(\mathrm{P}<0.05)$. There was no significant difference in the frequency of CAs in male rather than female babies. The incidence of CAs was significantly higher amongst the LBW ( $<2500 \mathrm{~g}$ ) babies than among normal birth weight babies. CAs were observed significantly more in preterm babies than full term $(\mathrm{P}<0.05)$. Examples of the discovered congenital anomalies are shown in Figures 1-4. Parents gave their approval for the publication of photographic material.
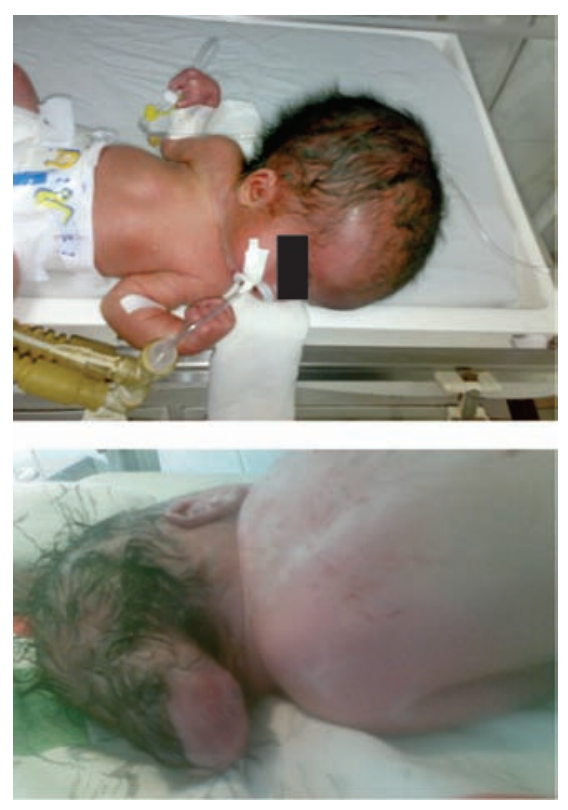

Figure 1. Congenital hydrocephalus, hand anomalies, encephalocele.

\section{Discussion}

With improved control of infections and nutritional deficiency diseases, CAs have become important causes of perinatal mortality in developed countries and will very soon become increasingly important determinates of perinatal mortality in developing countries. ${ }^{8}$

There are currently no reliable estimates of the number of children who were born with a serious congenital disorder due to genetic or environmental causes. Considerable uncertainty remains as to the incidence and the mortality related to congenital disorders, especially in countries that do not have an adequate registration system of deaths. However, these figures indicate that addressing the incidence and mortality associated with CAs needs to be linked to efforts to achieve the Millennium Development Goal 4 target, of a two-third reduction in the mortality rate of children under the age of 5 years between 1990 and 2015.1 In this hospital-based prospective

Table 1. Type of congenital malformations observed in patients $(n=74)$.

\begin{tabular}{|c|c|c|c|}
\hline System type & Malformations & N. & $\%$ \\
\hline \multicolumn{4}{|c|}{ Musculoskeletal ( $\mathrm{n}=14,19 \%)$} \\
\hline \multirow[t]{2}{*}{ Major } & Osteogenesis imperfecta & 1 & 1.03 \\
\hline & Spina bifida & 1 & 1.03 \\
\hline \multirow[t]{4}{*}{ Minor } & Talipes & 6 & 8.01 \\
\hline & Polydactyly & 2 & 2.07 \\
\hline & Syndactyly & 2 & 2.07 \\
\hline & Congenital hip dysplasia & 2 & 2.07 \\
\hline \multicolumn{4}{|c|}{ Central nervous ( $n=15,20.03 \%$ ) } \\
\hline \multirow[t]{5}{*}{ Major } & Hydrocephalus & 6 & 8.01 \\
\hline & Meningomyelocele & 4 & 5.04 \\
\hline & Encephalocele & 2 & 2.07 \\
\hline & Microcephaly & 2 & 2.07 \\
\hline & Anencephaly & 1 & 1.04 \\
\hline \multicolumn{4}{|c|}{ Gastrointestinal $(\mathrm{n}=12,16.02 \%)$} \\
\hline \multirow[t]{3}{*}{ Major } & Tracheo-esophageal fistula & 1 & 1.04 \\
\hline & Diaphragmatic hernia & 1 & 1.04 \\
\hline & Duodenal atresia & 1 & 1.04 \\
\hline \multirow[t]{4}{*}{ Minor } & Hare lip & 4 & 5.04 \\
\hline & Cleft palate & 2 & 2.07 \\
\hline & Imperforate anus & 1 & 1.04 \\
\hline & Inguinal hernia & 2 & 2.07 \\
\hline \multicolumn{4}{|c|}{ Genitourinary $(n=10,13.05 \%$ ) } \\
\hline \multirow[t]{2}{*}{ Major } & Amibigious genitalia & 1 & 1.04 \\
\hline & Hydronephrosis and ureterocele & 2 & 2.07 \\
\hline \multirow[t]{3}{*}{ Minor } & Hypospadius & 3 & 4.01 \\
\hline & Hydrocele & 2 & 2.07 \\
\hline & Undesended testis & 2 & 2.07 \\
\hline \multicolumn{4}{|c|}{ Craniofacial $(\mathrm{n}=8,10.08 \%)$} \\
\hline \multirow[t]{2}{*}{ Major } & Anophthalmia & 2 & 2.07 \\
\hline & Microphthalmia & 1 & 1.04 \\
\hline \multirow[t]{4}{*}{ Minor } & Ectropion & 1 & 1.04 \\
\hline & Hemangioma & 2 & 2.07 \\
\hline & Laryngeal web & 1 & 1.04 \\
\hline & Ranula & 1 & 1.04 \\
\hline \multicolumn{4}{|c|}{ Cardiovascular ( $\mathrm{n}=7,9.05 \%)$} \\
\hline \multirow[t]{4}{*}{ Major } & Patent ductus arteriosus & 2 & 2.07 \\
\hline & Atrial septal defect & 2 & 2.07 \\
\hline & Ventricular septal defect & 1 & 1.04 \\
\hline & Tetralogy of Fallots & 1 & 1.04 \\
\hline Minor & Single umbilical artery & 1 & 1.04 \\
\hline \multicolumn{4}{|c|}{ Miscellaneous/syndromes $(\mathrm{n}=8,10.08 \%)$} \\
\hline & Gastroschisis & 1 & 1.00 \\
\hline & Collodion baby & 1 & 1.00 \\
\hline & Exomphalos & 1 & 1.00 \\
\hline & Down & 3 & 4.01 \\
\hline & Edward & 1 & 1.04 \\
\hline & Turner & 1 & 1.04 \\
\hline
\end{tabular}


study, the overall incidence of CAs was 2.5\% (63 of 2517) of live born neonates. These findings are in accordance with the results of the European network of population-based registers for the epidemiological surveillance of congenital anomalies (EUROCAT) (2.4\%), ${ }^{9}$ Jones (2.3\%), 10 and Jehangir et al. 5 in a tertiary care hospital, who reported an incidence of $2.9 \%$. A lower incidence of CAs was found in Kuwait by Madi et al. ${ }^{11}$ who reported an incidence of $1.25 \%$, in India by Swain et al. ${ }^{8}$ who reported an incidence of $1.2 \%$, and in the United Arab Emirates. ${ }^{12}$ Furthermore, a lower incidence of CAs was reported in Egypt among live births and stillbirths: $1.16 \%$ in Alexandria and $1.58 \%$ in Cairo. ${ }^{13,14}$ It is still higher than that reported by the WHO in other populations (12.7 per 1000) in 16 countries. ${ }^{13}$ Other studies among live born neonates showed different prevalence figures; in Spain (20.23 per 1000), ${ }^{15}$ in Libyan Arab Jamahiriya (23.8 per $1000), 16$ in India (27.2 per 1000), ${ }^{17}$ and the Federal Republic of Germany where figures of $6.9 \%$ for major malformation and $35.8 \%$ for mild errors of morphogenesis were reported among live births, stillbirths and abortions. ${ }^{18}$

These variations in prevalence of CAs in various parts of the world might be explained by social and racial influences that are commonly known in genetic disorders. Also the results vary according to the background of the investigators, the type of sample studied and the period of observation. ${ }^{5}$

In this study, the most common system involved was the musculoskeletal system (19\%), followed by the CNS (20.3\%), GIT (16.2\%), genitourinary (13.5\%), craniofacial (10.8\%), CVS (9.5\%) and, lastly, miscellaneous and chromosomal anomalies (10.8\%). These findings were comparable to the studies conducted by other investigators in India, ${ }^{3}$ Kuwait, ${ }^{11}$ Saudi Arabia, ${ }^{19}$ and Iran. ${ }^{20}$ Some studies, however, recorded a higher incidence of CNS and CVS malformations followed by GIT and musculoskeletal system. ${ }^{21,22}$

The current study found that CAs prevailed in babies of consanguineous marriage, those babies born to under-nourished or obese mothers, those with a family history of an anomaly, and in low birth weight and/or preterm babies. On the other hand, maternal age and sex of the babies were not significantly associated with the development of CAs. In Saudi Arabia, Alshehri reported a high frequency of major CAs and stated that it might have resulted from the common habit of consanguineous marriages which has led to the preservation of rare mutations. ${ }^{19}$ The role of parental consanguinity for the development of CAs has been addressed by other studies.3,5,11,18,23 Although the incidence of CAs in the current study differed significantly among mothers of various age groups, many authors have shown a higher incidence of malformations in babies born
Table 2. Congenital malformations in relation to maternal and fetal factors.

\begin{tabular}{|c|c|c|c|c|}
\hline Factors & Total & $\begin{array}{c}\text { N. of malformed } \\
\text { neonates }\end{array}$ & $\%$ & $\mathbf{P}$ \\
\hline $\begin{array}{l}\text { Maternal age (years) } \\
\quad<20 \\
20-35 \\
>35\end{array}$ & $\begin{array}{c}120 \\
2107 \\
290\end{array}$ & $\begin{array}{c}3 \\
53 \\
7\end{array}$ & $\begin{array}{l}2.05 \\
2.05 \\
2.04\end{array}$ & $>0.05$ \\
\hline $\begin{array}{l}\text { Parental consanguinity } \\
\text { Consanguineous marriage } \\
\text { Non-consanguineous marriage }\end{array}$ & $\begin{array}{c}436 \\
2081\end{array}$ & $\begin{array}{l}15 \\
48\end{array}$ & $\begin{array}{l}3.04 \\
2.03\end{array}$ & $<0.05$ \\
\hline $\begin{array}{l}\text { Maternal nutrition } \\
\text { Nourished } \\
\text { Undernourished } \\
\text { Obesity }\end{array}$ & $\begin{array}{c}2096 \\
392 \\
29\end{array}$ & $\begin{array}{l}46 \\
15 \\
2\end{array}$ & $\begin{array}{l}2.02 \\
3.08 \\
6.09\end{array}$ & $<0.05$ \\
\hline $\begin{array}{l}\text { History of an anomaly in the family } \\
\text { Positive } \\
\text { Negative }\end{array}$ & $\begin{array}{c}270 \\
2247\end{array}$ & $\begin{array}{l}18 \\
45\end{array}$ & $\begin{array}{l}6.07 \\
2.00\end{array}$ & $<0.05$ \\
\hline $\begin{array}{l}\text { Sex } \\
\quad \text { Male } \\
\text { Female }\end{array}$ & $\begin{array}{l}1313 \\
1204\end{array}$ & $\begin{array}{l}34 \\
29\end{array}$ & $\begin{array}{l}2.06 \\
2.04\end{array}$ & $>0.05$ \\
\hline $\begin{array}{l}\text { Birth weight } \\
\quad<2500 \mathrm{~g} \\
\geq 2500 \mathrm{~g}\end{array}$ & $\begin{array}{l}1029 \\
1488\end{array}$ & $\begin{array}{l}36 \\
27\end{array}$ & $\begin{array}{l}3.05 \\
1.08\end{array}$ & $<0.05$ \\
\hline $\begin{array}{l}\text { Terms of pregnancy } \\
\text { Neonates at pre-term } \\
\text { Neonates at term }\end{array}$ & $\begin{array}{c}843 \\
1674\end{array}$ & $\begin{array}{l}28 \\
35\end{array}$ & $\begin{array}{l}3.03 \\
2.01\end{array}$ & $>0.05$ \\
\hline
\end{tabular}

$\mathrm{P}<0.05$ is statistically significant; $\mathrm{P}>0.05$ is statistically non-significant.
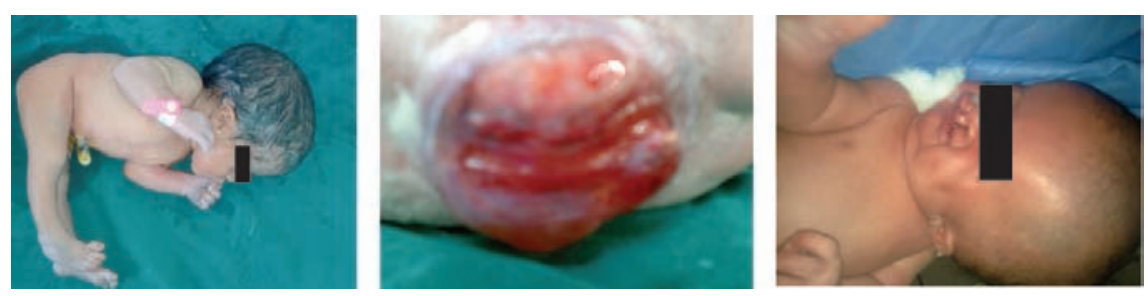

Figure 2. Congenital hydrocephalus and dorsolumbar meningeomyelocele; bilateral cleft lip and palate.
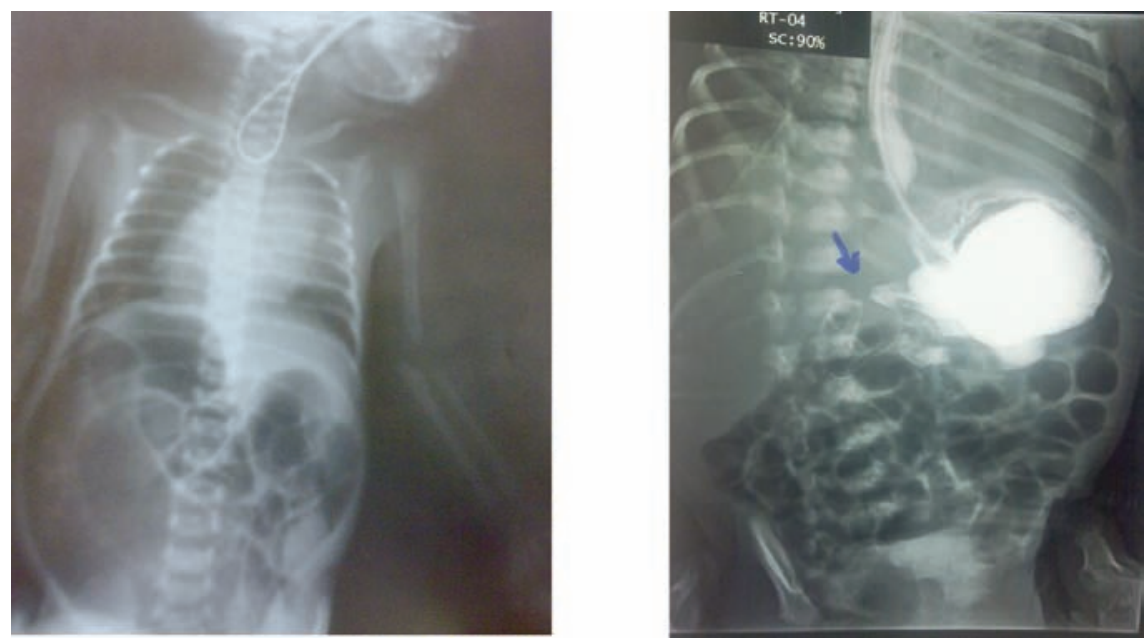

Figure 3. Plane chest and abdomen $\mathrm{X}$-ray. Coiled up orogastric tube; eosophageal atresia; gastrographin meal: doudenal atresia. 

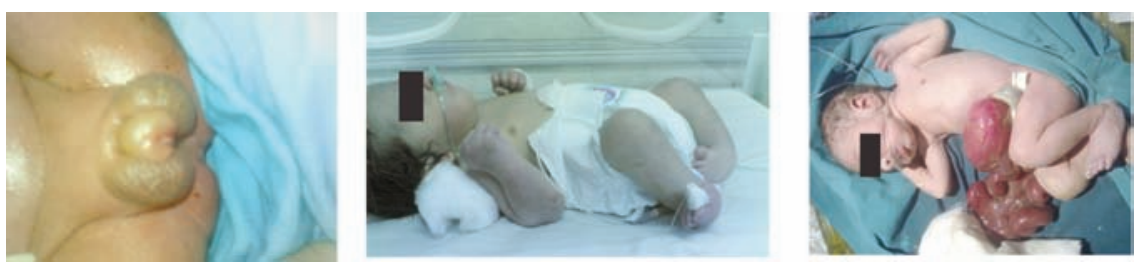

Figure 4. Ambigeous genitalia; bilateral club foot; gastroschisis.

to mothers aged under 20 years or in babies born to mothers aged over 35 years. ${ }^{3,8}$ On the other hand, Anjum et al. reported that the majority of neonates with CAs are born to mothers aged $25-38$ years. 23

Cassell and Golden studied maternal obesity as a risk factor for the development of CAs in the newborn. ${ }^{4}$ They reported that maternal obesity is significantly associated with an increased risk of selected birth anomalies such as spina bifida and heart defects.

In this study, the incidence of congenital malformations was significantly higher among the LBW babies in comparison to normal weight babies. This association of LBW and malformations has been well documented in other studies.3,5,8 Many studies have documented a male preponderance among congenital malformed babies.3,5,19,20 However, in the present series we could not observe any difference in predilection of malformations according to gender. On the other hand, Gupta et al. ${ }^{24}$ reported that the incidence of congenital musculoskeletal malformations was apparently found to be higher in female babies than in males; however, the difference was not statistically significant.

Regarding the gestational age of the malformed neonates, we found a significantly increased incidence of CAs among preterm neonates than full term. This is in accordance with reports by others..$^{5,10}$ Jones added that the risk factors associated with prematurity has proven increased frequency of CAs. ${ }^{10}$

\section{Conclusions}

This hospital-based prospective descriptive study highlighted the prevalence of congenital anomalies in one year in a university hospital in Egypt. It revealed a high prevalence of congenital anomalies in our locality and stressed the importance to carrying out a thorough clinical examination of all neonates at birth.

\section{References}

1. World Health Organization. Birth defects. Executive Board, 126th session, provisional agenda, December 2009; EB 126/10, 3. Available form: http://apps.who.int/gb/ebwha/pdf_files/EB1 26/B126_10-en.pdf

2. Tanteles GA, Suri M. Classification and etiology of birth defects. Pediatr Child Health 2007;17:233-43.

3. Singh A, Gupta RK. Pattern of congenital anomalies in newborn: a hospital based prospective study. JK Science 2009;2:34-6.

4. Cassell CH, Golden L. Epidemiology as a guardian of children's health: translating birth defects research into policy. Ann Epidemiol 2010;20:493-8.

5. Jehangir W, Ali F, Jahangir T, Masood MS. Prevalence of gross congenital malformations at birth in the neonates in a tertiary care hospital. APMC 2009;3:47-50.

6. Winter R, Baraitser M. The London dysmorphology database. Oxford: 0xford University Press; 1995.

7. World Health Organization. 1992. International Classification of Diseases and related health problems - Tenth Revision (ICD 10). Geneva: WHO. Available from: www.who.int/classifications/icd/en/

8. Swain S, Agrawal A, Bhatia BD. Congenital malformations at birth. Indian Pediatr 1994;31:1187-91.

9. Eurocat Report. 15 years of surveillance of congenital anomalies in Europe 19801992. Brussels: Eurocat Central Registry Institute of Hygiene and Epidemiology; 1997.

10. Jones KL. Smith's recognizable patterns of human malformation. Philadelphia: WB Saunders: 2005.

11. Madi SA, Al-Naggar RL, Al-Awadi SA, Bastaki LA. v. East Mediterr Health J 2005; 11:700-6.
12. Al-Ghazali LI. The profile of major congenital abnormalities in the United Arab Emirates (UAE) population. J Med Genet 1995;32:7-13.

13. Stevenson AC, Johnston HA, Stewart MI, et al. Congenital malformations. A report of series of consecutive births in 24 centers. Bull World Health Organ 1966;34 Suppl:9127.

14. Hafez M, El Sabrawy M, El Salab SH, et al. Study of congenital malformations in Egypt. Egyptian J Pediatr 1985;2:69-93.

15. Martínez-Frías ML, Cereijo A, Bermejo E, et al. Epidemiological aspects of Mendelian syndromes in a Spanish population sample: I. Autosomal dominant malformation syndromes. Am J Med Genet 1991;38:622-5.

16. Mir NA, Galezek WC, Soni A. Easily identifiable congenital malformations in children. Survey of incidence and pattern in 32332 live-born neonates. Ann Saudi Med 1992;12:366-71.

17. Verma M, Chhatwal J, Singh D. Congenital malformations: a retrospective study of 10,000 cases. Indian J Pediatr 1991;58:24552.

18. Queiber-Luft A, Stolz G, Wiesel A, et al. Malformations in newborn results based on 30940 infants and fetuses from Mainz congenital birth defect monitoring system (1990-1998). Arch Gynecol Obstet 2002; 266:163-7.

19. Al Shehri MA. Pattern of major congenital anomalies in South Western Saudi Arabia. Bahrain Med Bull 2005;27:302-7.

20. Ahmadzadeh A, Safikhani Z, Abdulahi M. Congenital malformations among livebirths at Atvand Hospital, Ahwaz, Iran. Pak Med J 2008;24:33-7.

21. Khatemi F, Mamorri GA. Survey of congenital major malformations in 10,000 newborns. Iranian J Pediatr 2005;15:315-20.

22. Isa AR, Masomeh K, Hamid-Reza F. The prevalence of overn congenital anomalies in Urmia, Iran. Arch Iran Med 2008;11:14851.

23. Anjum R, Saher S, Soomro N. Frequency of congenital anomalies and associated maternal risk factors. Pak J Surg 2006; 22:18-23.

24. Gupta RK, Gupta CR, Singh D. Incidence of congenital malformations of musculoskeletal system in new live borns in Jammu. JK Science 2003;5:157-60. 